\title{
The Effect of Thermo-mechanical Treatment on the High Temperature Tensile Behavior of an Alumina-forming Austenitic Steel
}

\author{
Bin Hu, Ian Baker \\ Thayer School of Engineering, Dartmouth College, Hanover NH 03755, USA
}

\begin{abstract}
Two different thermo-mechanical treatments (TMT) were performed on an alumina-forming austenitic (AFA) stainless steel, DAFA 29, which was recently developed at Oak Ridge National Laboratory for application in advanced ultra supercritical power plants. The resulting finegrained TMT materials showed yield stresses more than double the yield stress of the as-received material at room temperature and more than $50 \%$ higher at $600^{\circ} \mathrm{C}$, but lower yield stresses (but greater elongations) at $700^{\circ} \mathrm{C}$ and above. Strain rate jump tests performed at both $600^{\circ} \mathrm{C}$ and $700^{\circ} \mathrm{C}$ showed that the TMT materials have greater strain rate sensitivity and lower activation volumes at both temperatures. The strain rate has a power law relationship with the flow stress with a stress exponent of $\sim 5$. The as-received AFA alloy showed serrated stress-strain curves at $600^{\circ} \mathrm{C}$ suggesting the occurrence of dynamic strain aging.
\end{abstract}

Keywords

Alumina-forming Austenitic steel; Strain rate sensitivity; Activation volume; Strain rate jump tests; Deformation mechanism; Dynamic strain aging

Correspondence to: 14 Engineering Drive, Dartmouth College, Hanover, NH 03755, USA. Tel.: +1 603646 2184. E-mail address: Ian.Baker@dartmouth.edu (I. Baker). 


\section{Background}

An effective way to enhance the energy conversion efficiency and reduce the carbon footprint of fossil fuel power plants is to increase their operating temperature and pressure. The operating temperature and pressure of current ultra-supercritical (USC) power plants are $600^{\circ} \mathrm{C} / 25 \mathrm{MPa}$ which will eventually increase to $700^{\circ} \mathrm{C} / 35 \mathrm{MPa}$ and then later to $760^{\circ} \mathrm{C} / 35 \mathrm{MPa}$ for the next generation of advanced ultra-supercritical (A-USC) power plants [1-4]. The materials used for boiler/steam turbine in the A-USC power plant must be able to withstand not only this high operating temperature, but also excellent oxidation and corrosion resistance, most importantly at low cost $[4,5]$. This latter requirement is problematic for nickel and titanium alloys which are expensive.

Heat-resistant FeNi-based austenitic stainless steels could potentially be used for USC power plants due to their good creep, good oxidation resistance and relatively low cost. However, they rely on the formation of chromia $\left(\mathrm{Cr}_{2} \mathrm{O}_{3}\right)$ as the surface protection layer and this starts to lose its protective capability under aggressive environments at temperature above $\sim 650^{\circ} \mathrm{C}$ [6-8]. One potential solution is the development of alumina-forming austenitic (AFA) stainless steels. AFA stainless steels can form alumina scale on the material's surface. This alumina scale is more thermodynamically stable, grows slower than chromia $\left(\mathrm{Cr}_{2} \mathrm{O}_{3}\right)$, and it can provide better oxidation resistance than conventional heat resistant stainless steels in many harsh environments $[5,8-12]$.

Recently-developed AFA stainless steels exhibit the promising mechanical properties and oxidation resistance [8-14]. These AFA alloys fall in the composition ranges $\mathrm{Fe}-(12 \sim 35) \mathrm{Ni}$ (12 15)Cr-(2.5 4)Al-(0.6 3) Nb (wt.\%) with additions of $\mathrm{Nb}, \mathrm{Ti}, \mathrm{Si}, \mathrm{C}$, and $\mathrm{B}$ to improve the creep and oxidative properties [8]. They have a single phase austenitic microstructure with MC carbide and/or $\mathrm{Ll}_{2}-\mathrm{Ni}_{3}(\mathrm{Al}, \mathrm{Ti})$ as the main strengthening precipitates [11, 12]. The Laves phase on the grain boundaries also play an important strengthening role [13, 14]. Among these alloys, Fe-14Cr-32Ni-3Nb-3Al-2Ti (wt.\%), recently developed by Oak Ridge National Laboratory (ORNL) and referrer as DAFA29, with various minor elemental additions shows the best creep performance [12].

In a previous study, two TMTs were performed on DAFA29 in an attempt to further improve its mechanical properties. The microstructures and deformation behavior of this AFA alloy in both the as-received condition and after the TMTs were characterized at room temperature. The TMTs reduced the grain size significantly to the nanoscale $(\sim 100 \mathrm{~nm})$ and increased the room temperature yield strength to above $1000 \mathrm{MPa}$ [15].

In this paper, the deformation behavior of this AFA alloy in both the as-received condition and after the TMTs was studied at elevated temperatures. The flow stress of the TMT materials was evaluated at different strain rates, and the high temperature deformation mechanisms were characterized. 


\section{Experiment}

\subsection{Materials preparation}

The DAFA29 used in this study was obtained from ORNL (Oak Ridge, TN). Ingots of the alloys had been hot-rolled at $1100^{\circ} \mathrm{C}(80 \%$ thickness reduction with $\sim 15-20 \%$ thickness reduction per pass) and then annealed at $1100^{\circ} \mathrm{C}$ for $30 \mathrm{~min}$ in $\mathrm{Ar}+4 \% \mathrm{H}_{2}$ gas, followed by air-cooling. The chemical composition of this alloy, as analyzed using inductively coupled plasma spectroscopy and gas combustion techniques at ORNL, is shown in Table 1.

Two TMTs of the DAFA29 were performed in an attempt to produce finer and uniformly distributed precipitates [15]. In the first approach (referred to as Method \#1), the DAFA29 was cold rolled to a $90 \%$ reduction in thickness with a $\sim 4.5 \%$ reduction per pass, and then annealed at $800^{\circ} \mathrm{C}$ for $2.4,24$, or $240 \mathrm{~h}$. The grain sizes of the thermomechanically treated alloys ranged from $\sim 100 \mathrm{~nm}$ to $\sim 1 \mu \mathrm{m}$ depending on different annealing time. In the second approach (referred

to as Method \#2), the alloy was given a solutionizing anneal at $1200^{\circ} \mathrm{C}$ and then cold rolled to a $90 \%$ reduction in thickness with a $\sim 4.5 \%$ reduction per pass before annealing at $800^{\circ} \mathrm{C}$ for 2.4 , 24 , or $240 \mathrm{~h}$. As the annealing time was increased from 2.4 to $240 \mathrm{~h}$, the grain size increased from $\sim 200 \mathrm{~nm}$ to $\sim 2 \mu \mathrm{m}$. The as-received DAFA29 has a grain size of $\sim 40 \mu \mathrm{m}$ with niobium enriched precipitates $(\sim 10 \mu \mathrm{m})$ randomly distributed in the matrix and grain boundaries. After TMT, finer and uniformly distributed precipitates $(\sim 560 \mathrm{~nm})$ are present. Details of the microstructures of these thermo-mechanical treatments were described in a previous paper [15].

\subsection{Mechanical testing}

Tensile test specimens were milled to dog-bone geometry with a gauge length of $10 \mathrm{~mm}$, width of $2.65 \mathrm{~mm}$, thickness of $0.8 \mathrm{~mm}$, and polished to a mirror finish using 800 grit silicon carbide papers followed by $0.3 \mu \mathrm{m}$ alumina powder.

Elevated temperature $\left(600^{\circ} \mathrm{C}, 700^{\circ} \mathrm{C}\right.$ and $\left.800^{\circ} \mathrm{C}\right)$ tensile tests were performed with an Instron 5690 tensile testing machine and a MTS hydraulic testing machine. A preload force of $50 \mathrm{~N}$ was applied before the tensile tests. The initial strain rate for all tensile tests was $5 \times 10^{-4} \mathrm{~s}^{-1}$. Elongations were measured directly from the gauge of the specimens after the tensile tests. All the tensile tests were performed three times for each specimen. The resulting test data are shown as true stress- true strain curves.

Strain rate jump tests were performed on the same tensile test machine at $600^{\circ} \mathrm{C}$ and $700^{\circ} \mathrm{C}$. A preload force of $50 \mathrm{~N}$ was again applied before the strain rate jump tests were started. The initial strain rate for all strain rate jump tests was $5 \times 10^{-5} \mathrm{~s}^{-1}$.

2.3 Microstructural analysis 
For scanning electron microscope (SEM) analysis, samples were polished using increasingly fine grades of silicon carbide papers and then further polished using $0.3 \mu \mathrm{m}$ alumina powders to obtain a mirror finish. The polished samples were polished with a vibrometer (Buehler, Lake Bluff, IL) for 3 hrs. The specimens were then examined in an FEI XL-30 field emission gun (FEG) SEM operated at $15 \mathrm{keV}$, using backscattered electron (BSE) image mode.

Thin foils for transmission electron microscope (TEM) examination were produced from $3 \mathrm{~mm}$ dia., $200 \mu \mathrm{m}$ thick discs by twin-jet electropolishing at $9.5 \mathrm{~V}$ and $\sim 100 \mathrm{~mA}$ in a solution of $25 \%$ nitric acid in methanol at $-20^{\circ} \mathrm{C}$ using a Struers Tenupol 5. The resulting thin foils were examined using an FEI Tecnai F20 FEG TEM operated at $200 \mathrm{kV}$ and equipped with energy dispersive X-ray spectroscopy (EDS).

\section{Results}

\subsection{Tensile tests at elevated temperatures}

Tensile tests of TMT Method\#1 alloys were performed at $700^{\circ} \mathrm{C}$. The stress strain curves of the three TMT alloys are shown in Figure 1a. All three TMT alloys show lower yield strength but higher elongation compared to the as-received DAFA29, see Table 2. The tensile behaviors of these TMT alloys at $700^{\circ} \mathrm{C}$ are significantly different from room temperature. They show yield strength above $1000 \mathrm{MPa}$ in room temperature tensile tests [15].

Tensile tests of TMT alloys Method\#2 were also carried out at $700^{\circ} \mathrm{C}$. The stress strain curves of the three TMT alloys are shown in Figure 1b. The results are similar to the stress strain curves observed for the TMT Method\#1 tests. All the TMT alloys show lower yield strength, but higher elongation. The yield strengths (measured as $0.2 \%$ proof stress) were in the range of $270-346$ MPa, see Table 2.

After the tensile tests at $700^{\circ} \mathrm{C}$, all test specimens were characterized using the SEM. All the treated samples have different shapes of the necked region because of differences in ductility. TMT (Method\#1) alloys after ageing for $2.4 \mathrm{~h}, 24 \mathrm{~h}$ and $240 \mathrm{~h}$ showed reductions in area of $33 \%$, $64 \%$, and $93 \%$, respectively. The differences in the reduction in area are due to the different grain sizes for these three treated samples [15]. The grain sizes of TMT (Method\#1) annealed for $2.4 \mathrm{~h}, 24 \mathrm{~h}$ and $240 \mathrm{~h}$ samples are $\sim 100 \mathrm{~nm}, \sim 270 \mathrm{~nm}$, and $\sim 1 \mu \mathrm{m}$, respectively [15]. Thus, the elongation and reduction in area increased with increasing grain size, presumably due to the reduction in yield strength.

For TMT alloys treated using Method\#2, the reductions in area for the $2.4 \mathrm{~h}, 24 \mathrm{~h}$ and $240 \mathrm{~h}$ samples were $49 \%, 67 \%$ and $91 \%$, respectively. The microstructures of these TMT alloys were shown in our previous work in [15]. The grain size of TMT samples with ageing $2.4 \mathrm{~h}, 24 \mathrm{~h}$ and $240 \mathrm{~h}$ are $\sim 200 \mathrm{~nm}, \sim 450 \mathrm{~nm}$, and $\sim 2 \mu \mathrm{m}$, respectively. The $240 \mathrm{~h}$ annealed TMT alloy also has the largest area reduction and the highest elongation up to $53 \%$ due to the grain growth to larger than $2 \mu \mathrm{m}$ during $800^{\circ} \mathrm{C}$ annealing [15]. 
Figure 2 shows fracture surfaces of as-received DAFA29, TMT $2.4 \mathrm{~h}, 24 \mathrm{~h}$ and $240 \mathrm{~h}$ samples after tensile testing at $700^{\circ} \mathrm{C}$. The fracture surface of as-received DAFA29 shows ductile failure with large ductile dimples and considerable plastic deformation between the dimples. The fracture surfaces of TMT alloys are covered with a thick layer of oxide due to exposure at high temperature during the tensile tests. However, the Laves phase precipitates, which show white contrast, are still visible. There are no dimples evident on the fracture surface for all three TMT alloys, although the materials are all much more ductile than as-received DAFA29. This ductility is due to the small grain sizes (ranging from $\sim 100 \mathrm{~nm}$ to $1 \mu \mathrm{m}$ ) of these three TMT samples. All three fracture surfaces are coved by a layer of oxide formed during tensile test at $700^{\circ} \mathrm{C}$

As-received and TMT DAFA29 samples were also tested at elevated temperatures from $600^{\circ} \mathrm{C}$ to $800^{\circ} \mathrm{C}$. The resulting true stress-strain curves are shown in Figure 3. At $600^{\circ} \mathrm{C}$ (Figure $3 \mathrm{a}$ ), the stress strain curve of as-received DAFA29 has a yield stress of $535 \mathrm{MPa}$, shows considerable work-hardening and an ultimate tensile strength of $665 \mathrm{MPa}$ at an elongation of $20 \%$. The TMT alloys showed higher yield strengths of 928 and $886 \mathrm{MPa}$ for Method\#1 and Method\#2, respectively. At $800^{\circ} \mathrm{C}$, the yield strength of as-received DAFA29 decreased to $360 \mathrm{MPa}$ with no work-hardening evident. The yield strength of TMT alloys decreased dramatically lower to 150 (Method\#1) and $120 \mathrm{MPa}($ Method\#2) with elongations more than 40\%.

Figure 4 provides a summary of the yield stress of as-received and TMT DAFA29 tested at different temperatures. The behavior of as-received DAFA29 is similar to many f.c.c. alloys reported in the literature $[3,16]$, i.e.: nickel-base superalloys and nickel iron-base superalloy. The yield strength is not greatly affected by the increase in temperature until it reaches a certain temperature. This transition temperature is $600^{\circ} \mathrm{C}$ for the as-received DAFA29. The flow stress of $\mathrm{L}_{2}$ precipitates increase anomalously with increase of temperature. Therefore, the temperature independence of the yield strength of AFA alloys until $600^{\circ} \mathrm{C}$ is the net effect of strength reduction of f.c.c. phase compensated by the increase of strength from $\mathrm{L}_{2}$ precipitates [17].

The TMT AFA alloys show yield stresses significantly larger than the as-received DAFA29 at room temperature. This is due to the fine grain size present after the TMT process for both TMT methods $(100-200 \mathrm{~nm})$. Details of the room temperature tensile test results were described in previous paper [15]. As the temperature increased to $600^{\circ} \mathrm{C}$, the yield stress of the TMT alloys decreased gradually until $600^{\circ} \mathrm{C}$ and then decreased dramatically at $700^{\circ} \mathrm{C}$. This significant loss of stress in the range of $600^{\circ} \mathrm{C}$ to $700^{\circ} \mathrm{C}$ might be due to increased diffusion rates in TMT alloys leading to fast dislocation climb. The large volume of grain boundaries in TMT alloys lose the function to interrupt of dislocation motion due to the fast dislocation climbing. The grain boundaries work as sites of weakness at above $600^{\circ} \mathrm{C}$.

At $800^{\circ} \mathrm{C}$, this grain boundary effect is more obvious. The yield strength of TMT alloys is less than half of the yield strength of as-received DAFA29 as shown in Figure 4. At this temperature, dislocations will be able to move around obstacles easily, the grain refined TMT alloys become significantly weaker. 


\subsection{Strain rate jump tests at elevated temperatures}

Generally, the flow stress of alloys at elevated temperature is a function of the applied strain rate. The magnitude of the effect is expressed by the strain rate sensitivity $m$. Theoretically, it is possible to carry out a series tensile tests at various temperatures and strain rates. In practice, this is rarely done because of the limitations of time and the numbers of specimens required. Instead, strain rate jump tests can be performed using a single specimen. The strain rate is increased to a second level (approximately an order of magnitude) once a steady state flow stress is obtained.

Strain rate jump experiments were performed on as-received and TMT DAFA29 at $600^{\circ} \mathrm{C}$. The strain rate jump test results are shown in Figure 5a. The initial strain rate was $5 \times 10^{-5} \mathrm{~s}^{-1}$ with an order of magnitude increase for each jump. The flow stresses of both TMT alloys increased with the strain rate increases. But, the flow stress of as-received DAFA29 is relatively independent of strain rate at this temperature. It is insensitive to the strain rate change at $600^{\circ} \mathrm{C}$. It is worth noting the serrations that occurred on the as-received DAFA29 during testing at $600^{\circ} \mathrm{C}$. The serrated flow starts when the strain rate jumps from $5 \times 10^{-5} \mathrm{~s}^{-1}$ to $5 \times 10^{-4} \mathrm{~s}^{-1}$. It is thought to be related to dynamic strain aging in this material. We will further explain these serrations in the discussion section.

Strain rate jump tests were also performed at $700^{\circ} \mathrm{C}$ which is the target application temperature for AFA stainless steels. The results of strain rate jump tests of as-received and TMT DAFA29 performed are shown in Figure 5b. The initial strain rate was $5 \times 10^{-5} \mathrm{~s}^{-1}$ with an order of magnitude increase for each jump. The flow stresses of all samples increased with the strain rate increasing. At the strain rate of $5 \times 10^{-5} \mathrm{~s}^{-1}$, the flow stress of as-received DAFA29 was 445 $\mathrm{MPa}$ which is almost twice that of TMT DAFA29 of $292 \mathrm{MPa}$. When the strain rate is jumped to $5 \times 10^{-2} \mathrm{~s}^{-1}$, the flow stress of as-received DAFA29 was $829 \mathrm{MPa}$, which is less than that of TMT DAFA29 of $1080 \mathrm{MPa}$.

\subsection{Strain rate influence on microstructures}

In order to understand the fracture behavior of as-received DAFA29 at different strain rates, tensile tests of as-received DAFA29 alloys were performed at $700^{\circ} \mathrm{C}$ for selected strain rates $(5 \times$ $10^{-6} \mathrm{~s}^{-1}, 5 \times 10^{-4} \mathrm{~s}^{-1}$, and $5 \times 10^{-2} \mathrm{~s}^{-1}$ ). The resulting true stress-strain curves are shown in Figure 6 . The flow stresses are comparable to the results from the strain rate jump test results shown in Figure 5. Both the yield strength and work-hardening rate increase with increasing strain rate. A summary of the yield strengths and work-hardening rates is shown in Table 3.

TEM observations were used in order to investigate the dislocation distributions at $700^{\circ} \mathrm{C}$. Figure 7 shows bright field (BF) TEM images for the samples tested at different strain rates. The sample (Figure 7a) tested at $5 \times 10^{-2} \mathrm{~s}^{-1}$ has the highest dislocation density compared to the other two samples. The high dislocation density in Figure 7 a effectively enhanced the dislocation interactions which created additional barriers in the lattice for slip. These barriers produced the high work hardening rate observed at this strain rate (Figure 6). For the lower strain rates, the 
dislocation density was also lower. The samples tested at both $5 \times 10^{-4}$ and $5 \times 10^{-6} \mathrm{~s}^{-1}$ show no work hardening and lower dislocation densities. The dislocations in Figure $7 \mathrm{a}$ are observed to align along one direction. This might due to the high strain rate during the tensile test.

In Figure $7 \mathrm{c}, \mathrm{Fe}_{2} \mathrm{Nb}$ Laves phase and $\mathrm{NiAl}$ precipitates are present. These precipitates are located on grain boundaries and they are generated during the low strain rate test. Small $(\sim 26 \mathrm{~nm})$ spherical $\mathrm{L1}_{2}-\mathrm{Ni}_{3}(\mathrm{Al}, \mathrm{Ti})$ precipitates are also uniformly distributed in the f.c.c. matrix. The dislocations show strong interactions with these $\mathrm{L}_{2}$ precipitates. Numerous dislocation loops around $\mathrm{L} 1_{2}$ precipitates are present. The pinning effects of the precipitates result in the observed wavy dislocations. On the grain boundaries, numerous dislocations are crowded around the $\mathrm{Fe}_{2} \mathrm{Nb}$ Laves phase suggesting that the Laves phase precipitates are very strong obstacles to dislocation motion.

\section{Discussion}

At $700^{\circ} \mathrm{C}$, the yield strength of as-received DAFA29 is $523 \mathrm{MPa}$ and it is slightly lower than its room temperature yield strength 560MPa [15]. It work-hardens significantly with an elongation of $20 \%$ at room temperature, while it shows low work-hardening rate at $700^{\circ} \mathrm{C}$ with an elongation of $28 \%$.

The TMT alloys show lower yield strength $(\sim 390 \mathrm{MPa})$ but higher elongation compared to the asreceived DAFA29, see Figure 1 and 4. It is evident that the TMTs which result in a fine grain size significantly improve the room temperature properties, but this grain size strengthening is negligible at $700^{\circ} \mathrm{C}$. In room temperature, assuming off-set stress $\sigma_{0}$ is constant for all TMT alloys, the estimate grain size strengthening effect is $\sim 600 \mathrm{MPa}$ according to the $\Delta \sigma=K D^{-1 / 2}[15$, $18]$.

As the temperature increased to $700^{\circ} \mathrm{C}$, the strengthening effect becomes negligible due to the weakness of grain boundaries. For the $2.4 \mathrm{~h}$ annealed samples, the TMT method \#1 alloy still showed higher strength than TMT method \#2 alloy at $700^{\circ} \mathrm{C}$ although it has more grain boundaries (smaller grain size). This is mainly because the high temperature strength of TMT alloys has a strengthening contribution from the small Laves phase precipitates as well as the grain boundaries. The Laves phase precipitates in TMT method \#1 alloys are in the range of 167 $\pm 37 \mathrm{~nm}$ which is slightly smaller than it is in TMT method \#2 alloys (175 $\pm 45 \mathrm{~nm})$ [15].

For all the annealed specimens, the $2.4 \mathrm{~h}$ and $24 \mathrm{~h}$ annealed TMT method\#1 alloys shows higher yield strength compared to TMT method\#2 alloys due to a smaller grain size. When the annealing time was increased to $240 \mathrm{~h}$, TMT method\#2 alloys have higher strength than TMT method\#2. This might be due to an increase in the volume fraction of the Laves phase during the long time aging process. After $240 \mathrm{~h}$ aging, the large Laves phase precipitates in TMT method\#2 alloys are not present. Instead smaller Laves phase are precipitated out with size of $\sim 560 \mathrm{~nm}$ [15]. In TMT method\#1 alloys, there are still large Laves phase precipitate present in the microstructure. 
The following section will discuss the strain rate sensitivity of the as-received and TMT DAFA29. The deformation mechanism at elevated temperature will also be discussed based on the flow stress and strain rate for each alloy. Table 4 summarizes the flow stress at different strain rates for the as-received and TMT DAFA29 alloys.

\subsection{Strain rate sensitivity}

The flow stress and strain rate are typically related at a constant elevated temperature by the following equation:

$$
\sigma=C \dot{\varepsilon}^{m}
$$

where $\mathrm{C}$ is a constant, $\sigma$ is the flow stress, $\dot{\varepsilon}$ is the strain rate, and $m$ is the strain rate sensitivity parameter.

Based on the flow stress results shown in Table 4, the flow stress is plotted as a function of strain rate on a $\log -\log$ scale in Figure 8 . The strain rate sensitivity $m$ can be obtained from

$$
m=\frac{\log (\sigma)}{\log (\dot{\varepsilon})}
$$

The $m$ value can be obtained based on a linear fit as shown in Figure 8. $m$ of as-received DAFA29 is 0.12, while the values for TMT DAFA29 is 0.18 (Method\#1) and 0.19 (Method\#2), i.e. the yield stresses of the TMT DAFA29 alloys are more sensitive to strain rate compared to the as-received DAFA2 2 at $700^{\circ} \mathrm{C}$. The slight difference in $m$ values for TMT Method\#1 and Method $\# 2$ is probably due to different grain sizes [15]. At $600^{\circ} \mathrm{C} \mathrm{m}$ for as-received DAFA29 is 0.02, whereas the $\mathrm{m}$ values for the TMT AFA alloys are 0.08 (Method\#1) and 0.09 (Method\#2). All the $m$ values obtained at $600^{\circ} \mathrm{C}$ are much smaller than those obtained at $700^{\circ} \mathrm{C}$, indicating that the strain rate sensitivity is influenced by the temperature for all tested alloys.

At both $600^{\circ} \mathrm{C}$ and $700^{\circ} \mathrm{C}$, the alloys treated by Method\#2 with a grain size of $\sim 200 \mathrm{~nm}$ have a slightly higher $m$ than alloys treated by Method\#1. Alloys treated by Method\#1 have a grain size of $\sim 100 \mathrm{~nm}$ which is about half size of alloys treated by Method\#2. It shows an increase in strain rate sensitivity with decreasing grain size. This trend has also been observed in other nanocrystalline alloys $[19,20]$.

At the same testing temperature, the strain rate sensitivity is larger for the smaller nano-sized grains in the TMT alloys compared to coarse grains of $\sim 40 \mu \mathrm{m}$ for the as-received DAFA29. A number of models $[19,21,22]$ indicate a grain size dependence of the strain rate sensitivity is related to a decrease in the activation volume $V$.

The strain rate sensitivity $m$ can also be expressed as [20,21, 23]:

$$
m=\frac{\sqrt{3} k T}{V \sigma}
$$


where $k, T, V$ and $\sigma$ are Boltzman constant, absolute temperature, activation volume and yield/flow stress, respectively. The activation volume $V$ is directly related to the physical mechanisms of plastic deformation.

The activation volume $V$ can be calculated based on equations 2 and 3. A plot of $\log (\dot{\varepsilon}) / \log (\sigma)$ as function of $\sigma$ has a slope of $V / \sqrt{3} k T$ and activation volumes can be obtained based on the value of the slope. The activation volume for metals is normally expressed in terms of $b^{3}$, where $\mathrm{b}$ is the shortest burgers vector of a perfect dislocation. In f.c.c. iron the Burgers vector is 0.253 $\mathrm{nm}$ [24]. The calculated activation volumes for DAFA29 at $700^{\circ} \mathrm{C}$ is $1.1 \mathrm{~b}^{3}$, while the values for the TMT alloys are $0.7 \mathrm{~b}^{3}$ (Method\#1) and $0.8 \mathrm{~b}^{3}$ (Method\#2) respectively. The activation volume for the fine grained TMT alloys is smaller than that of the coarse-grained alloys. Dislocations have a higher activation barrier when the grain size enters the nanometer regime. This is similar to other alloys tested at both room temperature and elevated temperature [24-26].

\subsection{Deformation mechanisms}

The relationship between strain rate and stress of the precipitation-strengthened alloys at elevated temperature can be described by a power law [7, 27]:

$$
\dot{\varepsilon}=A\left(\frac{G b D}{k T}\right)\left(\frac{\sigma}{G}\right)^{n}
$$

where $\mathrm{G}$ is shear modulus, $\mathrm{b}$ is Burgers vector, $\mathrm{D}$ is diffusion coefficient of the f.c.c. matrix, $k$ is the Boltzmann constant, $\mathrm{T}$ is absolute temperature, and $\mathrm{n}$ is the stress exponent. A stress exponent $n$ in the range of 3-5 is typical for solid solution alloys. Specifically, $n$ is 5 for nickel and nickel-chromium alloys [27-29]. For precipitate-strengthened alloys, the $n$ values obtained are normally larger than the solid solution alloys [30]. The high stress exponent arising from small dispersed precipitates being obstacles to the movement of dislocations [31,32].

In order to reduce the high stress exponent values, a threshold stress term $\sigma_{t}$ is introduced into equation 4 to account for the influence of the precipitates. The effective stress is defined as $\sigma-\sigma_{\mathrm{t}}$. Thus, equation 4 can be rewritten as:

$$
\dot{\varepsilon}=A^{\prime}\left(\frac{G b D}{k T}\right)\left(\frac{\sigma-\sigma_{t}}{G}\right)^{n}
$$

The value of the threshold stress $\sigma_{t}$ depends on the dislocation precipitate interaction mechanism. The mechanism could be dislocation cutting, Orowan looping, or dislocation climb. This value can be determined using the methodology suggested by Lagneborg and Bergman [33]. Basically, equation 5 can be rewritten:

$$
\dot{\varepsilon}^{1 / n}=A^{\prime \prime}\left(\sigma-\sigma_{t}\right)
$$

| The threshold stress $\sigma_{\mathrm{t}}$ can be obtained from a plot of $\dot{\varepsilon}^{1 / n}$ as a function of $\sigma$, as shown in Figure 9 and the threshold stress is the $\mathrm{x}$-intercept. The threshold stress obtained using this method is 
$217 \mathrm{MPa}$ for as-received DAFA29 at $700^{\circ} \mathrm{C}$, which is similar to the threshold stress value measured in another AFA alloy tested at the same temperature [7]. The threshold stresses are 50 MPa (Method\#1) and $9 \mathrm{MPa}$ (Method\#2) for the TMT alloys tested at $700^{\circ} \mathrm{C}$. These values increase to $670 \mathrm{MPa}$ (Method\#1) and $574 \mathrm{MPa}$ (Method\#2) for the TMT alloys tested at $600^{\circ} \mathrm{C}$. Table 5 provides a summary of threshold stresses for the different processing conditions. The threshold stress of alloys treated by Method\#1 is slightly larger than Method\#2 for both temperatures. The value of the threshold stress decreased significantly with an increase in temperature, is almost zero for alloys treated by Method $\# 2$ at higher temperature.

Figure 10 shows plot of strain rate as a function of effective stress $\left(\sigma-\sigma_{t}\right)$ for the as-received and TMT DAFA29 alloys. The corrected $n$ value is 4.2 for the as-received DAFA29 tested at $700^{\circ} \mathrm{C}$ which is close to the stress exponent value of another AFA alloy reported in [7]. At $600^{\circ} \mathrm{C}$, the $n$ values of treated alloys decrease to 4.9 and 5.0 which are typical of $n$ values for solid solution alloys [34].

The extrapolated threshold stresses of the treated alloys at $600^{\circ} \mathrm{C}$ are much higher than those obtained at $700^{\circ} \mathrm{C}$. They decrease significantly with the increase in temperature of $100^{\circ} \mathrm{C}$. Three possible mechanisms are considered to explain the threshold stress in precipitation-strengthened alloys: 1) precipitate cutting, 2) Orowan dislocation bowing, 3) dislocation climbing [34] .

The Orowan dislocation bowing stress for dislocation interact with $\mathrm{Ni}_{3}(\mathrm{Al}, \mathrm{Ti})$ particles is

$$
\tau_{o}=\frac{G b}{L-2 r}
$$

where $\tau_{\mathrm{o}}$ is the shear stress necessary for precipitates bypass by Orowan bowing, $\mathrm{L}$ is particle spacing, $r$ is the radius of precipitates.

At $700^{\circ} \mathrm{C}$, the average size of $\mathrm{Ni}_{3}(\mathrm{Al}, \mathrm{Ti})$ precipitates is $35 \mathrm{~nm}$ after an $800^{\circ} \mathrm{C}$ anneal for $2.4 \mathrm{~h}$. The particle spacing obtained based on $\mathrm{L}$ and the volume fraction is $140 \mathrm{~nm}$ [15]. The volume fraction of $\mathrm{L1}_{2}$ phase can be calculated based on density and phase fraction from a JMatPro simulation shown in Figure 11. G is approximately $50 \mathrm{GPa}$ for AFA alloys and $\mathrm{b}$ is estimate to be $0.253 \mathrm{~nm}$. The calculated Orowan shear stress is about $180 \mathrm{MPa}$ for both TMT AFA alloys. The threshold stress values of TMT alloys are about $0.3 \tau_{\mathrm{o}}\left(50 \mathrm{MPa}\right.$ for Method\#1) and $0.05 \tau_{\mathrm{o}}(9$ MPa for Method\#2). These values are similar to those obtained from the Arzt-Ashby model for the local climb and general climb mechanisms [35]. For as-received DAFA29, the calculated Orowan shear stress is about $212 \mathrm{MPa}$ with a particle spacing of $120 \mathrm{~nm}$ and average particle size of $30 \mathrm{~nm}$. This Orowan stress is consistent with the threshold stresses of as-received DAFA29, which is $217 \mathrm{MPa}$.

At $600^{\circ} \mathrm{C}$, the threshold stress values are much higher than Orowan shear stress for both TMT alloys. This might be due to a change to a precipitate shearing mechanism and a higher volume fraction of $\mathrm{Ni}_{3}(\mathrm{Al}, \mathrm{Ti})$ at this temperature (Figure 11).

\subsection{Dynamic strain aging of DAFA29}


At $600^{\circ} \mathrm{C}$, the yield stress of as-received DAFA29 is insensitive to the strain rate, as shown in Figure 5a. The flow stress curve shows evidence of negative strain rate sensitivity with significant serrated flow. This serrated flow starts when the strain rate jumps from $5 \times 10^{-5}$ to $5 \times$

$10^{-4} \mathrm{~s}^{-1}$. This phenomenon is also observed for other stainless steels and high temperature superalloys [36-40]. The serrated flow is expected to be associated with dynamic strain aging (DSA) which occurs at certain combinations of temperature and strain rate [36, 40]. The occurrence of DSA is the result of solute diffusion in the metal lattice during plastic deformation at certain temperatures. The accumulation of these solute elements can impede the movement of dislocations and results in serrated flow curves. The solute elements typically responsible for this behavior are carbon below $550^{\circ} \mathrm{C}$, and $\mathrm{Cr}$ or Mo at temperatures above $550^{\circ} \mathrm{C}[40,41]$.

\subsection{DAFA29 is insensitive to strain rate at $600^{\circ} \mathrm{C}$}

The yield stress of DAFA29 is not dependent on the strain rate at $600^{\circ} \mathrm{C}$. This might be related to the work hardening of DAFA29 at this temperature. At $700^{\circ} \mathrm{C}$ or higher, there is little work hardening for DAFA29 as shown in Figure 1 and 2. The reduction of work hardening in asreceived DAFA29 at temperature of $700^{\circ} \mathrm{C}$ and higher temperature is due to a softening mechanism such as dynamic recovery which is expected to become the dominant mechanism at elevated temperature [38]. At higher temperatures, the work hardening due to the increase in dislocation density with increasing strain is counteracted by the formation of subgrains with low energy dislocations. Thermally-activated climb of dislocations is the prominent dynamic recovery mechanism for precipitate-strengthened alloys. This will overcome the obstacles of dislocation motion which is restrained at the lower temperature of $600^{\circ} \mathrm{C}$. This is also influenced by strain rate during tensile tests since the recovery is diffusion controlled process [38].

\section{Conclusions}

In this paper, the recently-developed AFA alloy, DAFA29, was treated by two TMT methods. The resulting fine-grained alloys were tensile tested at elevated temperature. Their mechanical properties were also evaluated by strain rate jump tests at two different temperatures. These results were compared to data for the as-received AFA alloy. The findings of this research are summarized as follows:

1. The TMT didn't increase the yield strengths of AFA alloys at $700^{\circ} \mathrm{C}$, although it significantly enhanced the yield strength of AFA alloys at room temperature.

2. The TMT AFA alloys have higher strain rate sensitivity and lower activation volume compared to as-received DAFA29 at elevated temperatures. The higher strain rate sensitivity and lower activation volume are due to the nanocrystalline grain size of the alloys.

3. For the two TMT AFA alloys, the strain rate and stress satisfy a power law relationship with the stress exponent around 5, whereas the stress exponent is around 4 for the asreceived DAFA29. These values ruled out the mechanisms of bulk diffusion (Nabarro- 
Herring mechanism) and grain boundary diffusion (Coble mechanism) to explain the flow behavior.

4. At $700^{\circ} \mathrm{C}$, dislocation climb is the dominant mechanism for deformation of TMT alloys. When the temperature decrease to $600^{\circ} \mathrm{C}$, the mechanism changes to dislocation shearing as indicated by the dramatically increased threshold stress.

5. The yield stress of TMT alloys decrease rapidly from $600^{\circ} \mathrm{C}$ to $700^{\circ} \mathrm{C}$, which might be because increased diffusion rates in TMT alloys lead to fast dislocation climb at $700^{\circ} \mathrm{C}$. At this temperature, dislocation will be able to move around obstacles easily and the large volume of grain boundaries in TMT alloys work as sites of weakness.

6. The flow stress of the as-received AFA alloy is insensitive to strain rate at $600^{\circ} \mathrm{C}$ due to strong work hardening at this temperature. It also shows significant serrated flow on the stress strain curve, which is associated with dynamic strain aging effect.

\section{Acknowledgments}

This research was supported by the U.S. Department of Energy under NETL Award DEFG2612FE0008857. The authors would like to acknowledge Dr. Yukinori Yamamoto and Dr. Michael P. Brady of ORNL both for providing the AFA stainless steels and for their insightful advice.

\section{References:}

[1] N. Evans, P. Maziasz, R. Swindeman, G. Smith, Scripta Materialia, 51 (2004) 503-507.

[2] R. Viswanathan, J. Henry, J. Tanzosh, G. Stanko, J. Shingledecker, B. Vitalis, R. Purgert, Journal of Materials Engineering and Performance, 14 (2005) 281-292.

[3] P.D. Jablonski, J.A. Hawk, C.J. Cowen, P.J. Maziasz, JOM, 64 (2012) 271-279.

[4] Z. Zhong, Y. Gu, Y. Yuan, Z. Shi, Metall and Mat Trans A, 45 (2014) 343-350.

[5] Y. Yamamoto, M.P. Brady, Z.P. Lu, P.J. Maziasz, C.T. Liu, B.A. Pint, K.L. More, H. Meyer, E.A. Payzant, Science, 316 (2007) 433-436.

[6] B.A. Pint, R. Peraldi, P. Maziasz, in: Materials Science Forum, Trans Tech Publ, 2004, pp. 815-822.

[7] D. Zhou, X. Xu, H. Mao, Y. Yan, T. Nieh, Z. Lu, Materials Science and Engineering: A, 594 (2014) 246-252.

[8] M.P. Brady, J. Magee, Y. Yamamoto, D. Helmick, L. Wang, Materials Science and Engineering: A, 590 (2014) 101-115.

[9] M.P. Brady, Y. Yamamoto, M.L. Santella, P.J. Maziasz, B.A. Pint, C. Liu, Z. Lu, H. Bei, JOM, 60 (2008) 12-18.

[10] H. Bei, Y. Yamamoto, M.P. Brady, M.L. Santella, Materials Science and Engineering: A, 527 (2010) 2079-2086.

[11] Y. Yamamoto, M.P. Brady, M.L. Santella, H. Bei, P.J. Maziasz, B.A. Pint, Metall and Mat Trans A, 42 (2011) 922-931.

[12] Y. Yamamoto, G. Muralidharan, M.P. Brady, Scripta Materialia, 69 (2013) 816-819.

[13] G. Trotter, I. Baker, Materials Science and Engineering: A, (2015).

[14] I. Tarigan, K. Kurata, N. Takata, T. Matsuo, M. Takeyama, in: MRS Proceedings, Cambridge Univ Press, 2011, pp. mrsf10-1295-n1206-1203. 
[15] B. Hu, G. Trotter, I. Baker, M.K. Miller, L. Yao, S. Chen, Z. Cai, Metall and Mat Trans A, 46 (2015) 3773-3785.

[16] R. Kozar, A. Suzuki, W. Milligan, J. Schirra, M. Savage, T. Pollock, Metall and Mat Trans A, 40 (2009) 1588-1603.

[17] Z. Zhong, Y. Gu, Y. Yuan, T. Yokokawa, H. Harada, Materials Characterization, 67 (2012) 101-111.

[18] K. Ma, H. Wen, T. Hu, T.D. Topping, D. Isheim, D.N. Seidman, E.J. Lavernia, J.M. Schoenung, Acta Materialia, 62 (2014) 141-155.

[19] M. Dao, L. Lu, R.J. Asaro, J.T.M. De Hosson, E. Ma, Acta Materialia, 55 (2007) 4041-4065.

[20] R.J. Asaro, S. Suresh, Acta Materialia, 53 (2005) 3369-3382.

[21] L. Capolungo, Atomistic and Continuum Modeling of Nanocrystalline Materials: Deformation Mechanisms and Scale Transition, Springer Science \& Business Media, 2010.

[22] S. Cheng, E. Ma, Y. Wang, L. Kecskes, K. Youssef, C. Koch, U. Trociewitz, K. Han, Acta Materialia, 53 (2005) 1521-1533.

[23] J. Chen, L. Lu, K. Lu, Scripta Materialia, 54 (2006) 1913-1918.

[24] F. Dalla Torre, P. Spätig, R. Schäublin, M. Victoria, Acta Materialia, 53 (2005) 2337-2349.

[25] Y.M. Wang, A.V. Hamza, E. Ma, Acta Materialia, 54 (2006) 2715-2726.

[26] Y. Wang, A. Hamza, E. Ma, Applied Physics Letters, 86 (2005) 241917.

[27] J.K. Benz, L.J. Carroll, J.K. Wright, R.N. Wright, T.M. Lillo, Metall and Mat Trans A, 45 (2014)

3010-3022.

[28] C. Allen, P. Delavignette, S. Amelinckx, Physica status solidi (a), 9 (1972) 237-246.

[29] A. Brown, M. Ashby, Scripta Metallurgica, 14 (1980) 1297-1302.

[30] O.D. Sherby, P.M. Burke, Progress in Materials Science, 13 (1968) 323-390.

[31] S. Zhu, S. Tjong, J. Lai, Acta Materialia, 46 (1998) 2969-2976.

[32] C. Stallybrass, A. Schneider, G. Sauthoff, Intermetallics, 13 (2005) 1263-1268.

[33] R. Lagneborg, B. Bergman, Metal Science, 10 (1976) 20-28.

[34] D.N. Seidman, E.A. Marquis, D.C. Dunand, Acta Materialia, 50 (2002) 4021-4035.

[35] E. Arzt, M.F. Ashby, Scripta Metallurgica, 16 (1982) 1285-1290.

[36] A.K. Roy, J. Pal, C. Mukhopadhyay, Materials Science and Engineering: A, 474 (2008) 363-370.

[37] W. Karlsen, M. Ivanchenko, U. Ehrnstén, Y. Yagodzinskyy, H. Hänninen, Journal of Nuclear Materials, 395 (2009) 156-161.

[38] K. Gopinath, A. Gogia, S. Kamat, R. Balamuralikrishnan, U. Ramamurty, Metall and Mat Trans A, 39 (2008) 2340-2350.

[39] J. Wright, J. Simpson, R. Wright, L. Carroll, T. Sham, in: ASME 2013 Pressure Vessels and Piping Conference, American Society of Mechanical Engineers, 2013, pp. V01AT01A053-V001AT001A053. [40] M. Hörnqvist, C. Joseph, C. Persson, J. Weidow, H. Lai, in: MATEC Web of Conferences, EDP Sciences, 2014, pp. 16002.

[41] A. Nagesha, S. Goyal, M. Nandagopal, P. Parameswaran, R. Sandhya, M. Mathew, S.K. Mannan, Materials Science and Engineering: A, 546 (2012) 34-39. 
Table 1 Analyzed chemistry (wt.\%) of as-received DAFA29 [15]

\begin{tabular}{cc}
\hline Element & wt.\% \\
\hline $\mathrm{Fe}$ & 45.34 \\
\hline $\mathrm{Cr}$ & 13.83 \\
\hline $\mathrm{Mn}$ & 0.13 \\
\hline $\mathrm{Ni}$ & 32 \\
\hline $\mathrm{Cu}$ & 0.12 \\
\hline $\mathrm{Al}$ & 3.02 \\
\hline $\mathrm{Si}$ & 0.15 \\
\hline $\mathrm{Nb}$ & 2.87 \\
\hline $\mathrm{V}$ & $<0.01$ \\
\hline $\mathrm{Ti}$ & 2 \\
\hline $\mathrm{Mo}$ & 0.1 \\
\hline $\mathrm{W}$ & $<0.01$ \\
\hline $\mathrm{Zr}$ & 0.32 \\
\hline $\mathrm{C}$ & 0.11 \\
\hline $\mathrm{B}$ & 0.0085 \\
\hline $\mathrm{P}$ & $<0.005$ \\
\hline $\mathrm{N}$ & $<0.0001$ \\
\hline
\end{tabular}



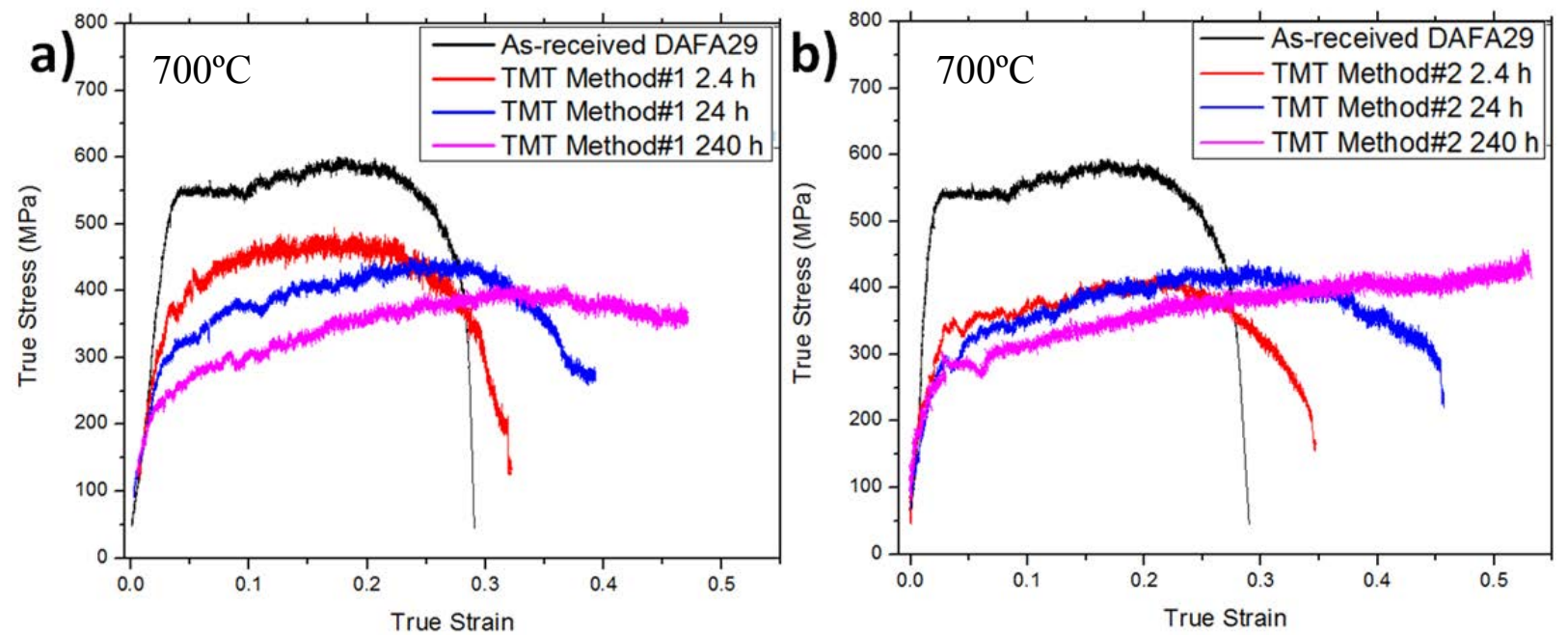

Figure 1 Stress strain curves of as-received and TMT DAFA29 at $700^{\circ} \mathrm{C}$, a) after TMT Method\#1, b) after TMT Method\#2. 
Table 2 Yield strength, elongation at fracture, and reduction in area at the neck for the asreceived and TMT DAFA29 after tensile tested at $700^{\circ} \mathrm{C}$

\begin{tabular}{ccccccc}
\hline Materials & \multicolumn{2}{c}{ TMT Method\#1 } & \multicolumn{3}{c}{ TMT Method\#2 } \\
\cline { 2 - 7 } & $\begin{array}{c}\text { Yield } \\
\text { Strength } \\
(\mathbf{M P a})\end{array}$ & $\begin{array}{c}\text { Elongation } \\
\mathbf{( \% )}\end{array}$ & $\begin{array}{c}\text { Reduction } \\
\text { in area } \\
\mathbf{( \% )}\end{array}$ & $\begin{array}{c}\text { Yield } \\
\text { Strength } \\
(\mathbf{M P a})\end{array}$ & $\begin{array}{c}\text { Elongation } \\
\mathbf{( \% )}\end{array}$ & $\begin{array}{c}\text { Reduction } \\
\text { in area } \\
\mathbf{( \% )}\end{array}$ \\
\hline As-received & 523 & 28 & 30 & 523 & 28 & 30 \\
\hline TMT 2.4h & 393 & 32 & 33 & 346 & 33 & 49 \\
\hline TMT 24h & 298 & 38 & 64 & 298 & 45 & 67 \\
\hline TMT 240h & 225 & 46 & 93 & 270 & 53 & 91 \\
\hline
\end{tabular}



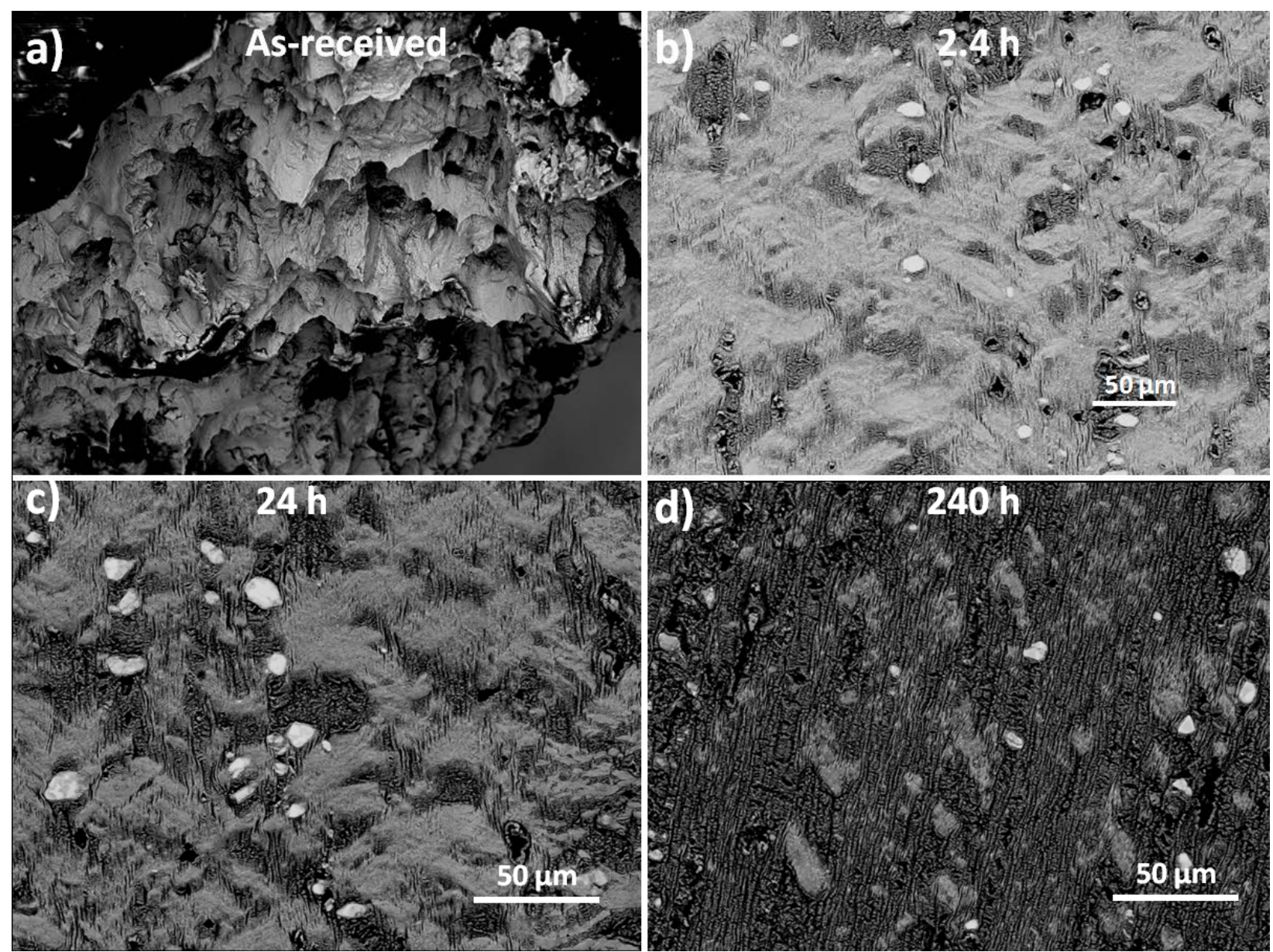

Figure 2 BSE images of fracture surfaces for as-received (a) and TMT DAFA29 (Method\#1, b is for $2.4 \mathrm{~h}$, c is for $24 \mathrm{~h}$ and $\mathrm{d}$ is for $240 \mathrm{~h}$ ) tensile tested at $700^{\circ} \mathrm{C}$ annealed for the times indicated. 

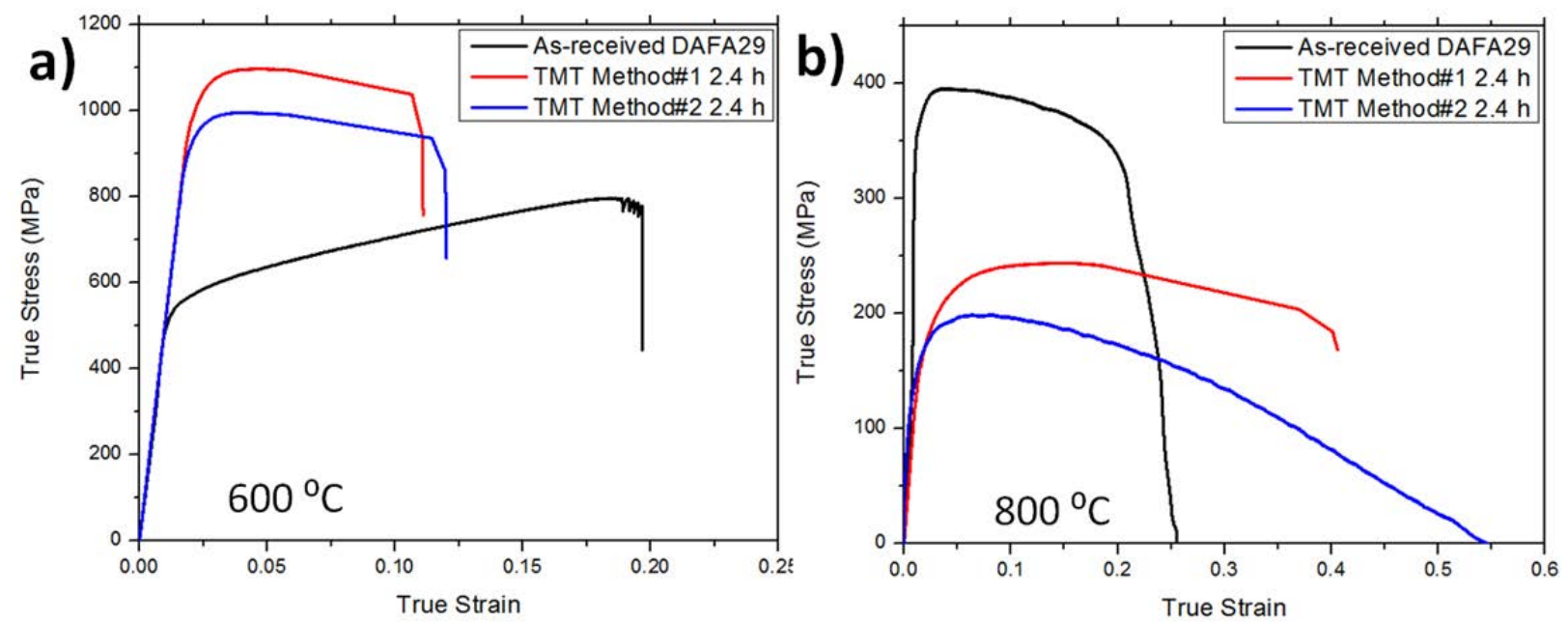

Figure 3 True stress-strain curves for as-received and TMT DAFA29 at $600^{\circ} \mathrm{C}$ (a) and $800^{\circ} \mathrm{C}(\mathrm{b}$ ). All the tensile tests were performed with an initial strain rate of $5 \times 10^{-4} \mathrm{~s}^{-1}$. 


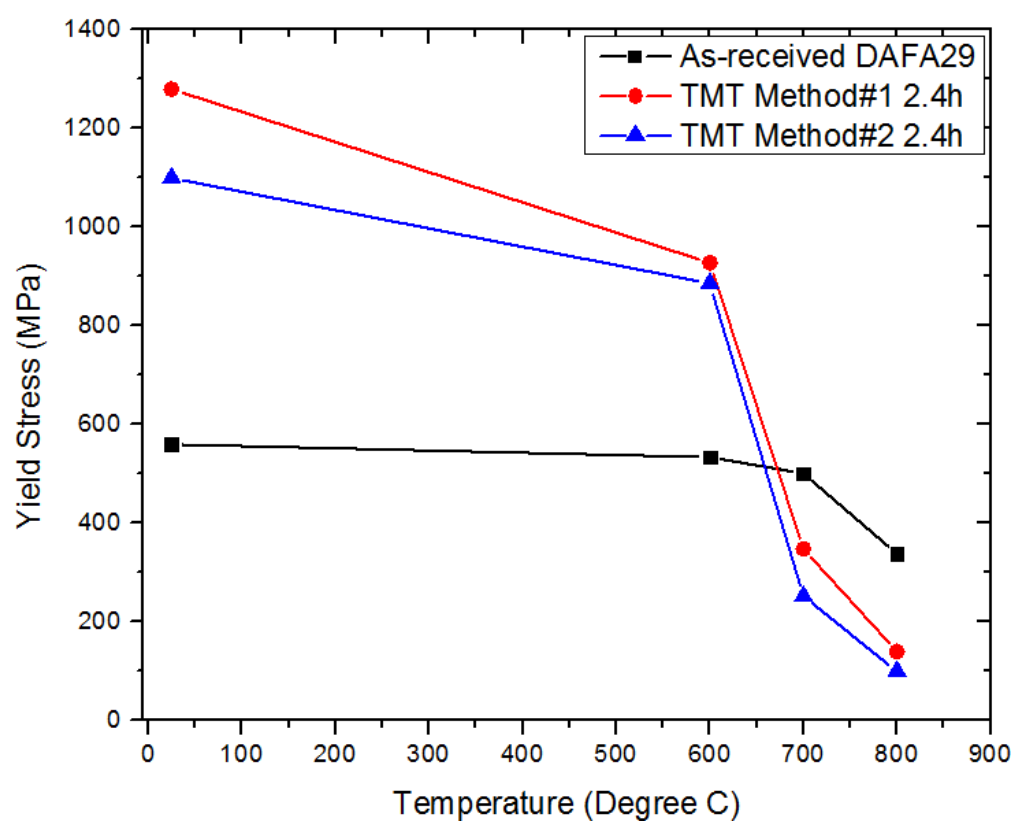

Figure 4 Yield stress of as-received DAFA29 and TMT DAFA29 (Method\#1 and Method\#2) as a function of temperatures (All the tests were performed at strain rate of $5 \times 10^{-4} \mathrm{~s}^{-1}$ ) 

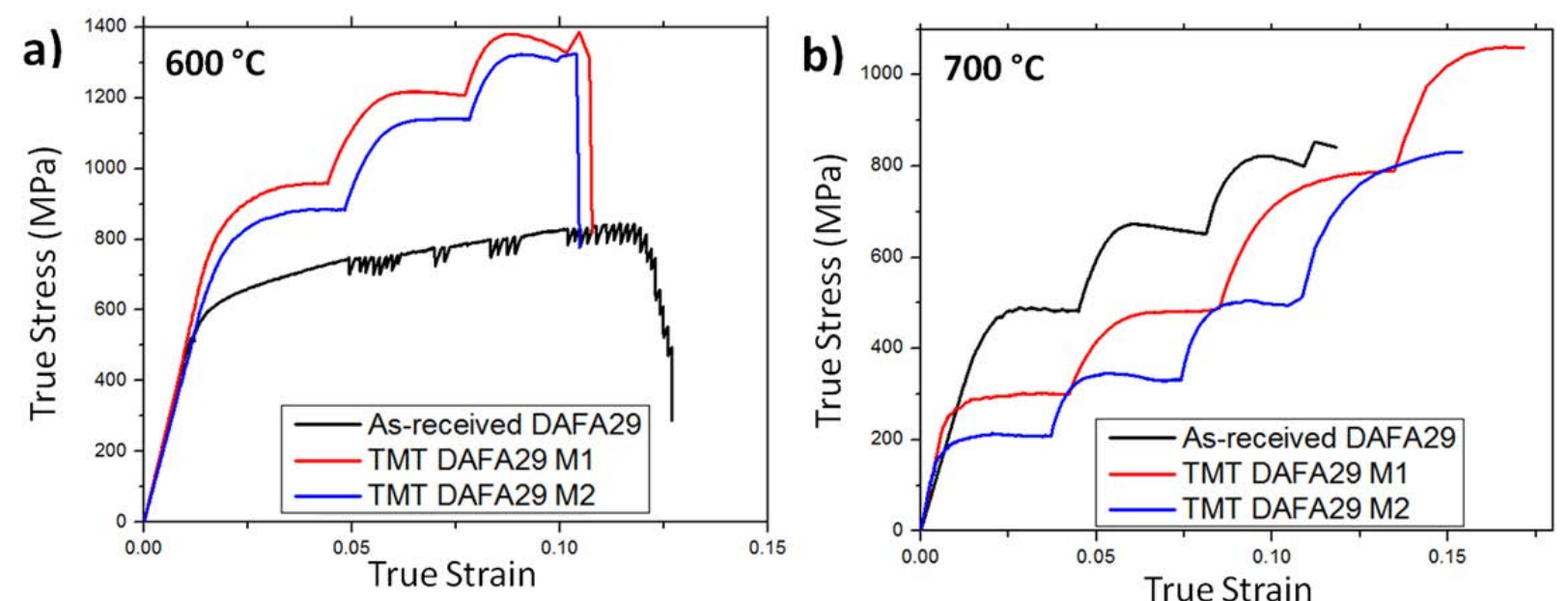

Figure 5 Strain rate jump tests of as-received and TMT DAFA29 (Method\#1 and Method\#2) at $600^{\circ} \mathrm{C}$ (a) and $700^{\circ} \mathrm{C}(\mathrm{b})$. Each strain rate jump is increased by an order of magnitude starting at an initial strain rate of $5 \times 10^{-5} \mathrm{~s}^{-1}$. 


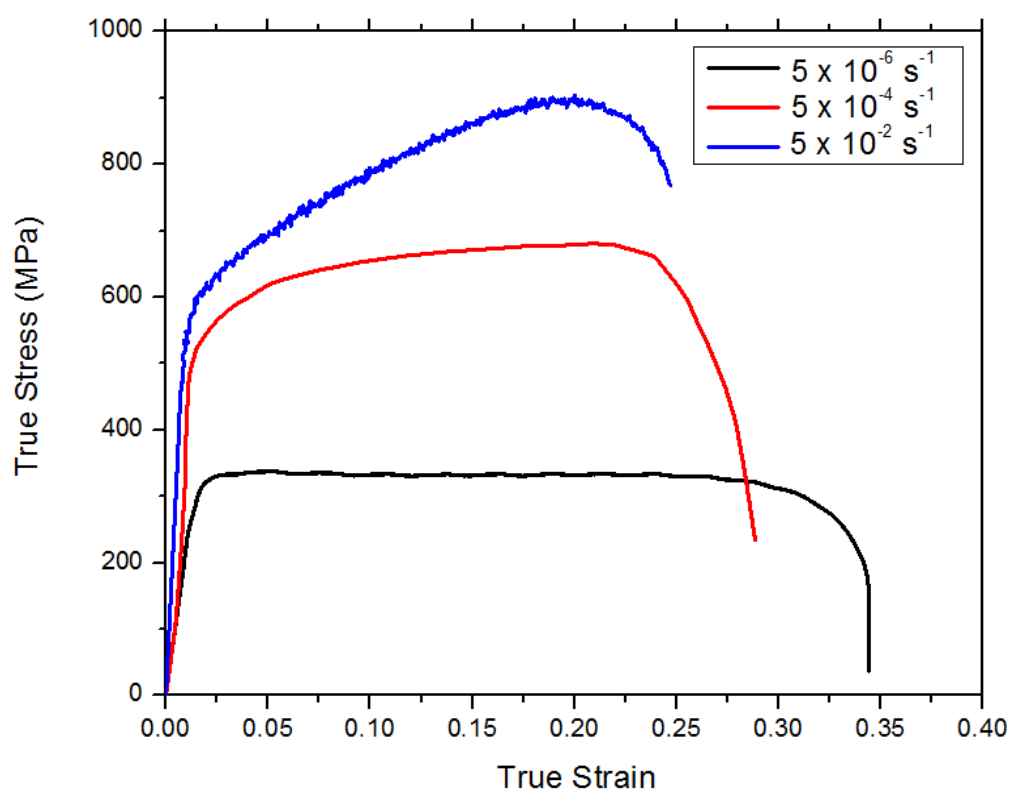

Figure 6 True stress-strain curves for as-received DAFA29 at different strain rates at $700^{\circ} \mathrm{C}$. 
Table 3 Yield strength and work-hardening rate of as-received DAFA29 at different strain rates

\begin{tabular}{ccc}
\hline Strain rate $\left(\mathbf{s}^{-1}\right)$ & Yield strength $(\mathbf{M P a})$ & Work-hardening rate $\mathbf{n}$ \\
\hline $5 \times 10^{-6}$ & 280 & 0 \\
\hline $5 \times 10^{-4}$ & 560 & 0.10 \\
\hline $5 \times 10^{-2}$ & 580 & 0.19 \\
\hline
\end{tabular}



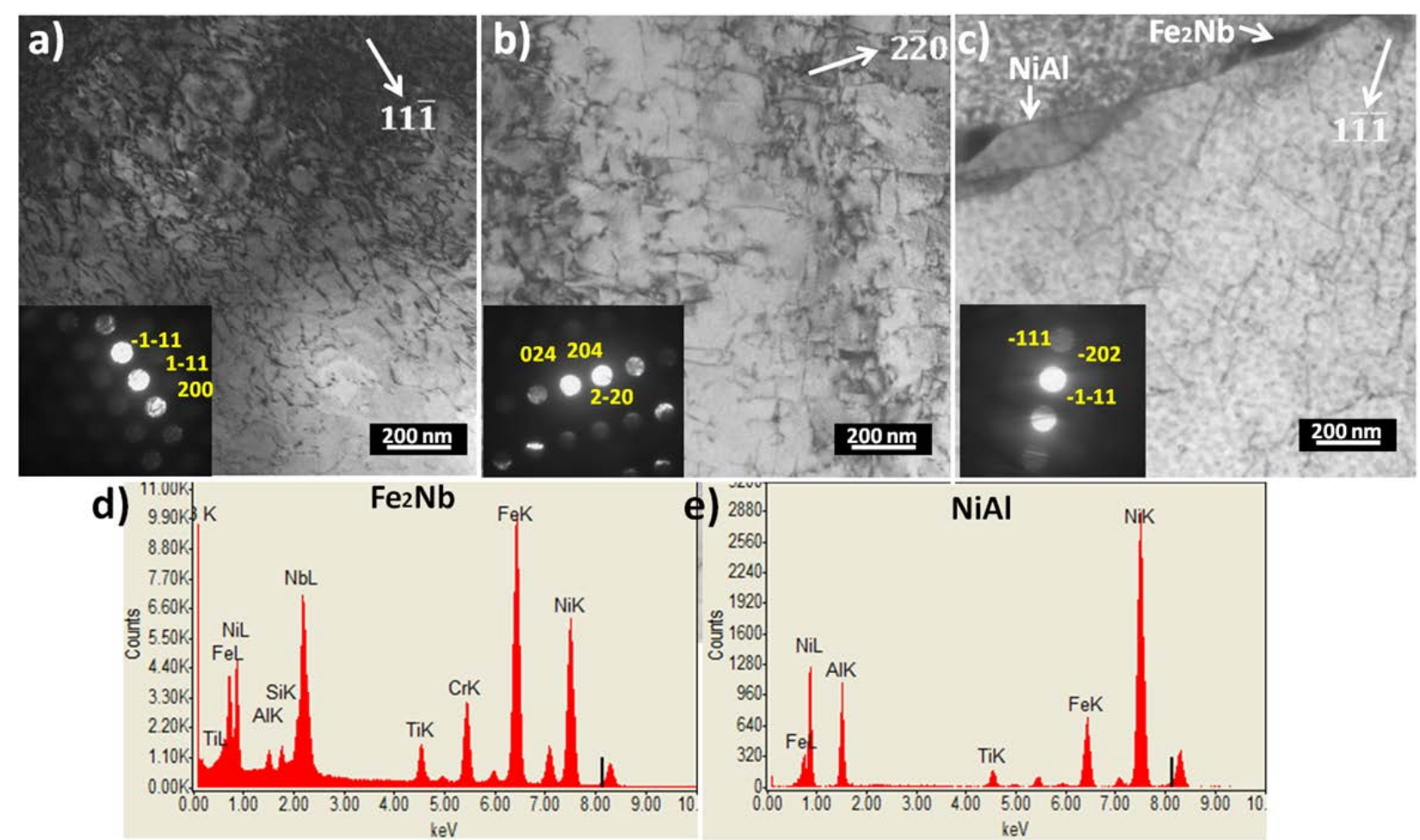

Figure $7 \mathrm{BF}$ TEM images of dislocations in DAFA29 after $700^{\circ} \mathrm{C}$ tensile tests at different strain rates: (a) $5 \times 10^{-2} \mathrm{~s}^{-1}$, (b) $5 \times 10^{-4} \mathrm{~s}^{-1}$, (b) $5 \times 10^{-6} \mathrm{~s}^{-1}$. (d) and (e) show EDS results from the grain boundary precipitates of $\mathrm{Fe}_{2} \mathrm{Nb}$ and $\mathrm{NiAl}$ for the sample tested at strain rate of $5 \times 10^{-6} \mathrm{~s}^{-1}$ 
Table 4 Summary of flow stress at different strain rate for the as-received and TMT DAFA29 at $600^{\circ} \mathrm{C}$ and $700^{\circ} \mathrm{C}$.

\begin{tabular}{|c|c|c|c|c|c|c|}
\hline \multirow{3}{*}{$\begin{array}{c}\text { Strain rate } \\
\qquad\left(\mathrm{S}^{-1}\right)\end{array}$} & \multicolumn{6}{|c|}{ Flow stress (MPa) } \\
\hline & \multicolumn{3}{|c|}{$600^{\circ} \mathrm{C}$} & \multicolumn{3}{|c|}{$7^{700}{ }^{\circ} \mathrm{C}$} \\
\hline & DAFA29 & Method\#1 2.4h & Method\#2 2.4h & DAFA29 & Method\#1 2.4h & Method\#2 2.4h \\
\hline $5 \times 10^{-6}$ & 742 & 958 & 885 & 341 & 301 & 214 \\
\hline $5 \times 10^{-4}$ & 792 & 1216 & 1138 & 489 & 482 & 346 \\
\hline $5 \times 10^{-3}$ & 828 & 1375 & 1322 & 673 & 789 & 505 \\
\hline $5 \times 10^{-2}$ & & & & 822 & 1061 & 831 \\
\hline
\end{tabular}



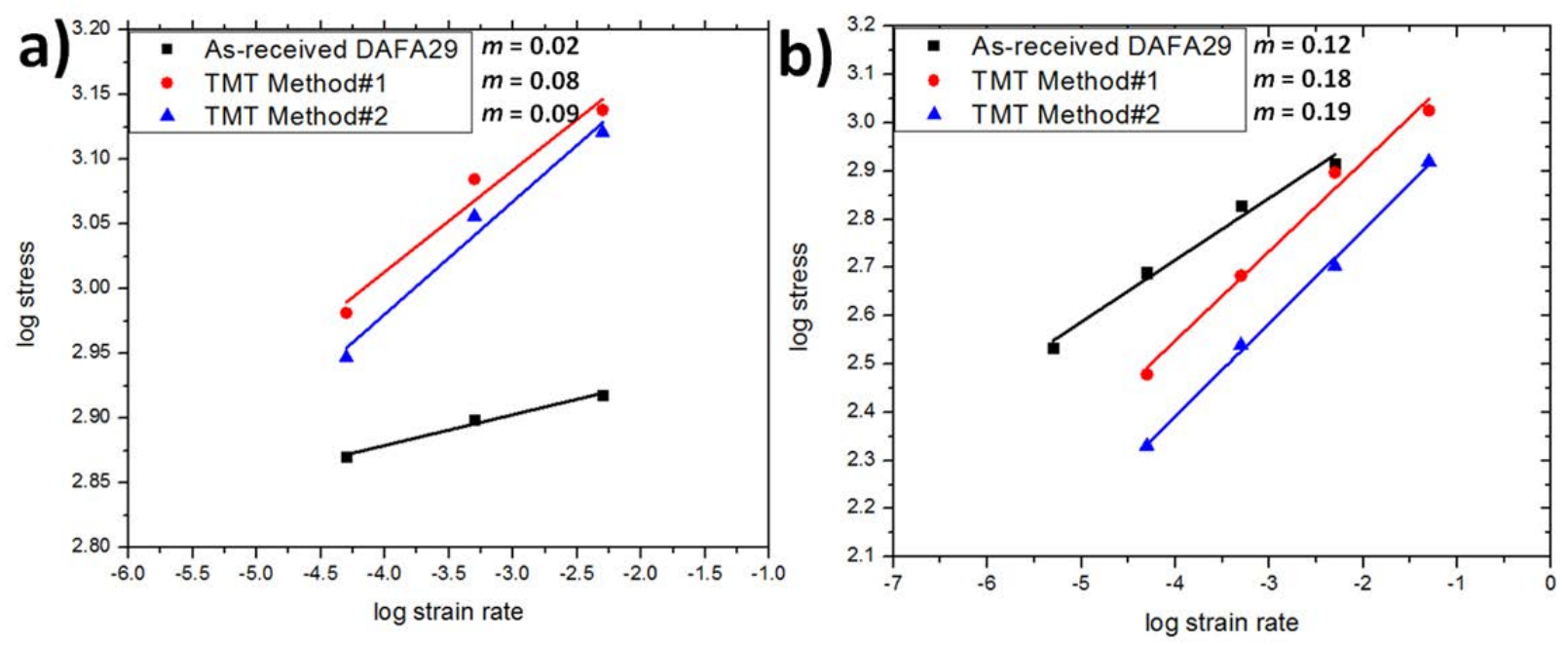

Figure 8 Stress as a function of strain on log-log scale plots from data obtained for alloys tested at (a) $600^{\circ} \mathrm{C}$ and (b) $700^{\circ} \mathrm{C}$. 
Table 5 Threshold stresses extrapolated from $\dot{\varepsilon}^{1 / 5}$ vs $\sigma$ plots

\begin{tabular}{cccc}
\hline \multirow{2}{*}{ Temperature $\left({ }^{\circ} \mathbf{C}\right)$} & \multicolumn{3}{c}{ Threshold Stress (MPa) } \\
\cline { 2 - 4 } & As-received DAFA29 & TMT Method\#1 & TMT Method\#2 \\
\hline $\mathbf{6 0 0}$ & -- & 670 & 574 \\
\hline $\mathbf{7 0 0}$ & 217 & 50 & 9 \\
\hline
\end{tabular}




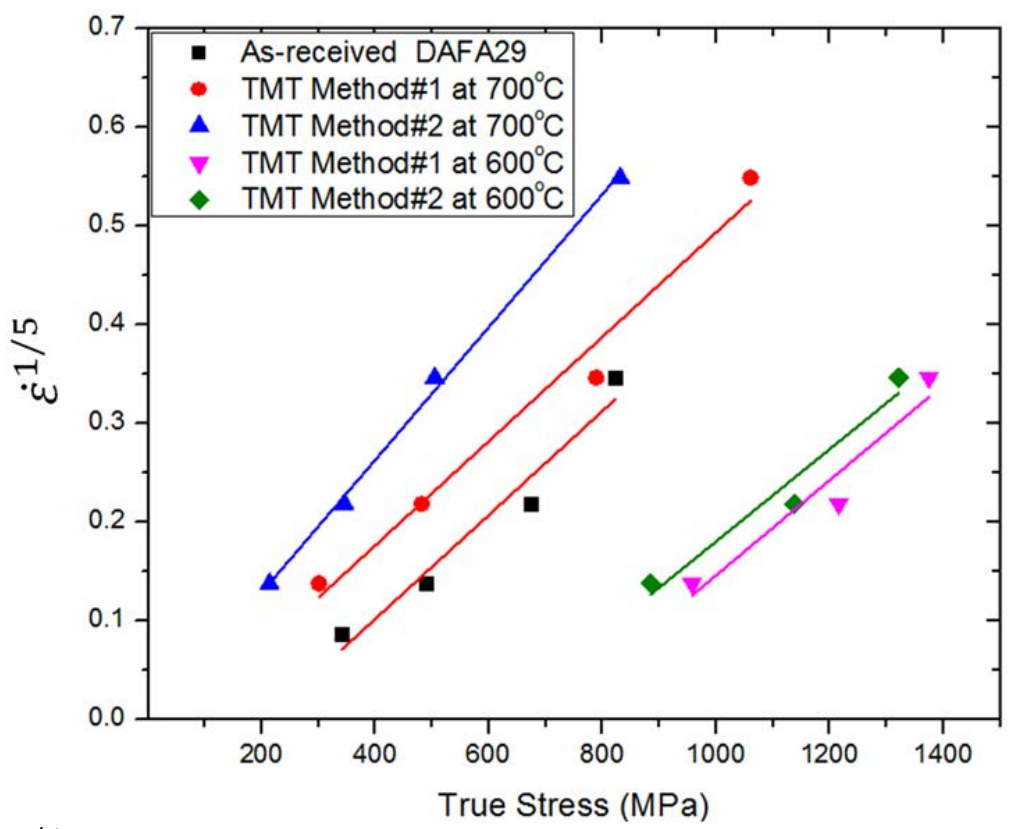

Figure 9 Plots of $\dot{\varepsilon}^{1 / 5}$ as a function of stress for as-received DAFA29 and the TMT alloys. 


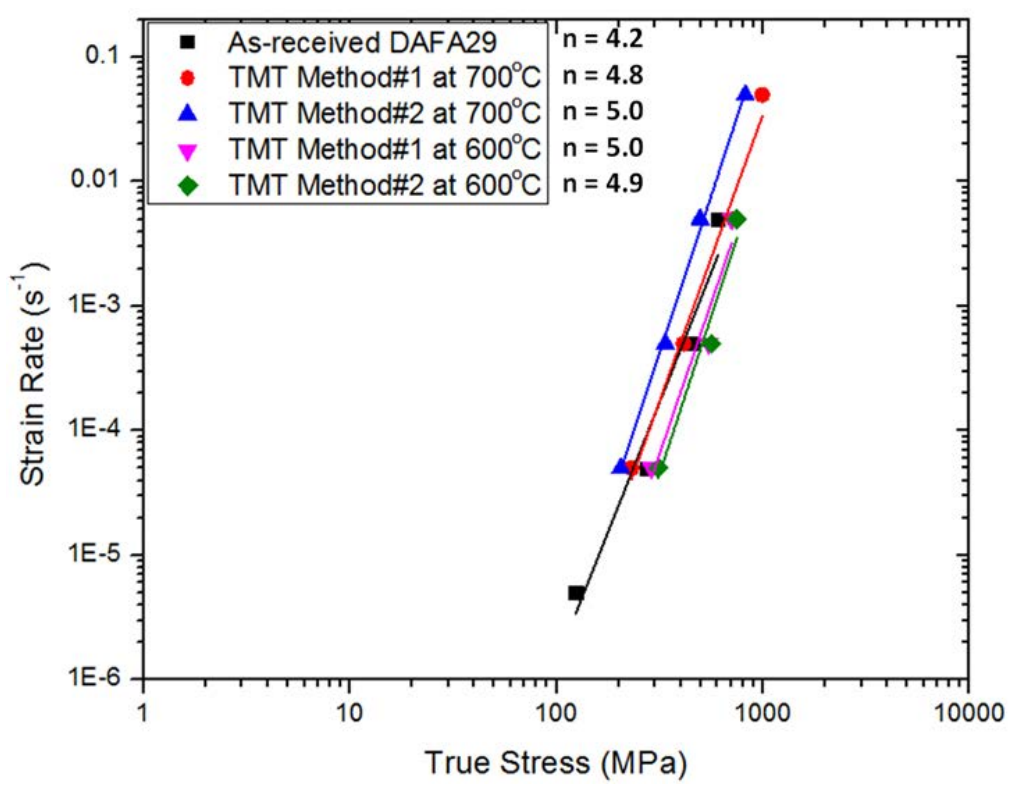

Figure 10 Strain rate as a function of the effective stress $\left(\sigma-\sigma_{t}\right)$ for as-received and TMT DAFA29 alloys. The plots are on log-log scales. 
Ni-3.0Al-14.0Cr-45.44Fe-3.0Nb-0.15Si-2.0Ti-0.3Zr-0.01B-0.1C wt(\%)

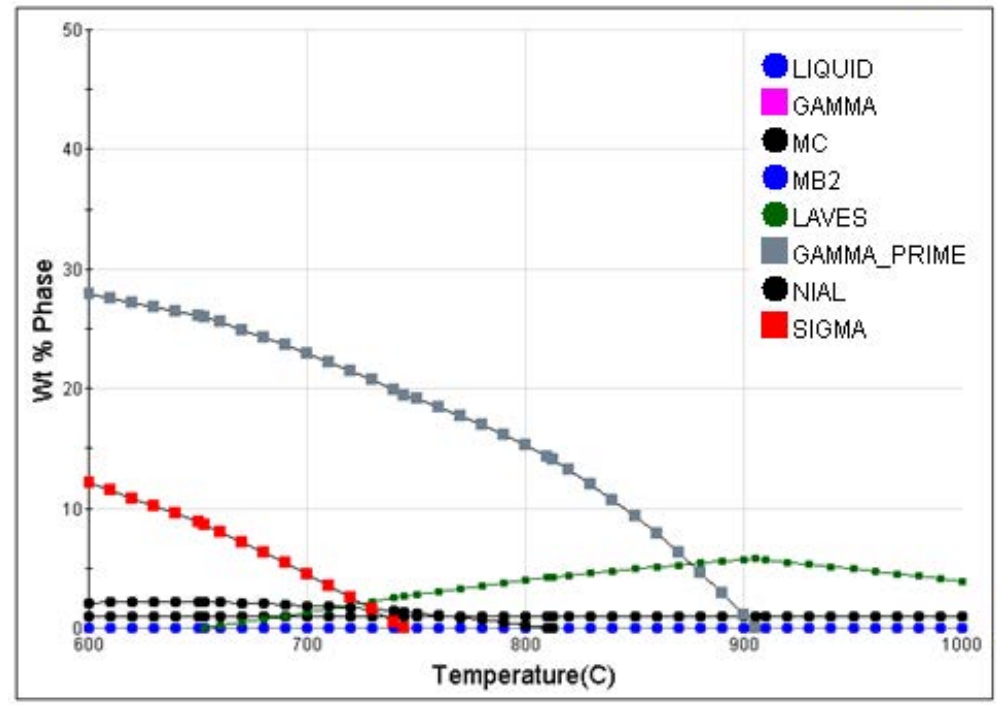

Figure 11 Phase fractions of different phases in DAFA29 alloys from a JMatPro simulation. 